\title{
Minimal Units in the Cinematographic Language
}

\author{
Sawsan Mohamed Ezzat Ibrahim Amer \\ An Associate Professor at Faculty of Applied Arts -October 6 University \\ Photography, Cinema and Television dep., Egypt
}

\begin{abstract}
Most of the pioneer of film semioticians spent their time looking for literal equivalences between linguistic and filmic units. Many discussions about the relation between double articulation and minimal units. Christian Metz is the first among pioneers of film-linguistic. Research problem, Metz says that analyses of the articulation of a "code" like lighting has no equivalent of the double articulation of natural language. So it has no minimal units. That is one of the reasons why Metz considered cinema as a language system not as a language. The research aim: will find out if the lighting has a minimal units or not. By analyses of the articulation of codes in lighting. Research significance: finding out the minimal units in single codes such as lighting assures linguistic cinema. The research follows inferential, descriptive methodology.
\end{abstract}

Key words: articulation; cinematography; lighting; signs; semiotics

\section{1- Introduction}

Semiotics allow the study of signs, the term sign means; something that is placed to replace another thing and it is used to transfer information, or say or point at something that is known by someone who wants to share his knowledge with others. Many of the pioneers studied cinema as a language, one of the most important pioneer was Christian Metz who realized through his studies that cinema is a language system and isn't a language. He relied on some conclusions, such as that cinema doesn't have minimal units similar to the ones in the language, such as "basic vocal units". The problem appeared in Metz's studies and others as they trapped the cinematic work and their movies' analysis inside the visual content that is projected on the screen while cinematic work actually starts from the first thought inside the mind of the screenwriter. (you can't limit the study of cinematic work to the final visual image of the projected movie), in addition; previous studies when talked about movies at pre-production stages concentrated only on directing and editing, may be that's due to the habit of handling the movie as a whole unit with its final look. While 


\section{1-23 February, $2020 \quad$ Rome, Italy}

cinema language is distinguished from other languages by having each unit of it that carries the message and each basic element of its units has a different meaning. That's when we need a pause to study that element. Does the singular "lighting unit $100 \mathrm{~K}$ " or "the short wavelength of the color red" has a meaning of its own? Could it be considered as the minimal unit so it matches all the other minimal units in the pronounced or written language?

At the first articulation the linguistic system is made of the minimal available units that have meaning which are the basic units of the meaning "morphemes", they are significant units (monemes), those significate units represent complete signs, each of them consists of signifier and signified, further analysis could be done on those units (monemes) till it reaches the meaningless state, as in the basic vocal units the phonemes that present within the $2^{\text {nd }}$ articulation at which the minimal unit appear.

The research is handling how far the accuracy of Metz's theory which he declared during his study of cinema linguistic, which resulted in the fact of him not dealing with cinema as a language. The research by inferential and descriptive methodology, studies the absence or presence of the minimal units in cinematography. To look for the minimal units in cinematography which resemble phonemes or graphemes, first we have to locate cinematographic main units that will be studied. Cinematography is based on 2 main elements which are lighting and color in addition to camera setting (the lens opening- film sensitivity- speed of closure-etc.).

The study handles the search for the basic filming units "cinemes" during its various primary elements that resemble the main vocal units "phonemes" or the main writing units "graphemes" which don't carry meaning within themselves.

\section{2- Main Units in Cinematography:}

\subsection{Units of light}

Cinematographer main mission is the lighting where he uses whether artificial or natural lighting and his main goal is giving the scene the exact amount of light that it needs to to be recorded on the sensitive medium, light has 3 other functions: Adding aesthetics to the image- adding reality- serving the drama of the film. Cinematographer uses the various available lighting units to achieve those goals such as led lights, dido lights, candles or sources of natural light that are presented in the shooting location.

\subsection{Color}

It is the second important element used by the Cinematographer that adds aesthetics and has many dramatic use. 


\subsection{Camera setting}

One of the mission of Cinematographer is tuning the camera, adjust it by choosing the right opening of the lens F.No- sensitivity of the used film/sensor.

\section{3- Entrance for studying the minimal units in cinema:}

What is meant by minimal units: the minimal units of the pronounced/written language such as phonemes and graphemes. Those units aren't considered signs on their own or by themselves, phonemes could be a part of a syllable, for example or the morphemes to be a part of a sentence or a novel, subsequently it will have a meaning. So they are units that carry the meaning in case they are combined together.

Metz thinks that there is nothing inside the movie that is resembling the concept of phonemes which totally rely on combining to produce units with meaning. Cinematic shots or even individual images are separately significant without relying on being combined. What Metz (Stam, et al., 1992, p.32) mentioned confirms his study limitation to the cinematic shot and he only considered it as the minimal unit in the movie which can be demolished by the following:

- The shot itself has many frames.

- Metz cancelled the whole pre- production and pre-editing processes from his study despite their maximum importance as they are the first and basic work that the whole movie is dependent on.

Pier Paolo Pasolini thinks that the minimal units of cinema that are equivalent to phonemes aren't changed in a movie by being reproduced, though; cinema language has its own kind of double articulation. Minimal units in cinema language as Pasolini says are the various realistic things that occupy the image and they are known as the "cinemes" which resemble the phonemes and they integrate in larger units that match the morphems in the regular language. (Stam, et al., 1992, p.32), but Pasolini never specified what are those minimal units. The research adopts Pasolini's term "cinemes" to express the minimal cinematic units during the research while the minimal cinematographic units, the researcher uses the term "photocinemes".

\section{4- Levels of meaning in cinematographic semiotic}

The term of levels of meanings is describing denotation and connotation. The first level of meaning (the first meaning of the sign) which belongs to denotation, at that level there is a sign made of signifier and signified. While connotation represents the second level of meaning (the second meaning of the sign) which uses donatative sign with its (signifier 


\section{1-23 February, $2020 \quad$ Rome, Italy}

and signified) as a signifier and that's how it gives an additional signified. From that perspective the connotation is a sign that derives its presence from the signifier that belongs to denotative sign so that the denotation leads to a series of connotation, Shape 1, and changes the signifier while keep the signified fixed, and a whole different connotation could be given, change the appearance could include additional different connotation. (Chandler, 2002, p:142)

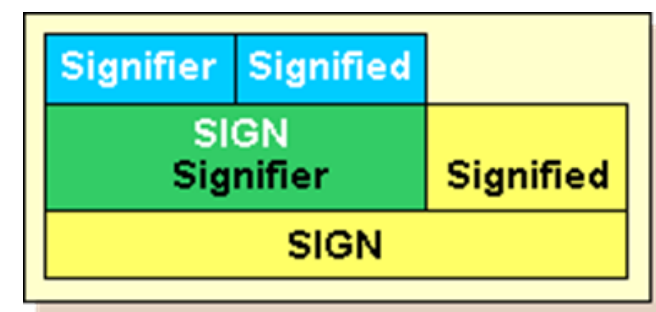

Shape 1

Shows the denotation and connotation as levels to produce the meaning. (Chandler, 2002, p:142)

\section{4-1- The previous shape of analyzing the levels of meanings allows the study of cinematography on two levels:}

The first level of meaning: is the level inside the mind of the cinematographer which consists of signifier and signified and forms the denotation. Assuming for example the cinematographer desire to create a mood of mystery in some shots, it is an idea that hasn't been realized yet, and it will be turned into signifier and signified once it is actually realized at the filming location through using certain lighting units, selecting the sensitivity of some film, certain lens opening and adding the required color. All those elements as a total represent the original signifier, while the original signified is the visual realization of the mental perception that the cinematographer wanted and executed at the filming location using the original signifiers.

The second level of meaning: the connotation is being formed after the movie is finally projected on screen, where the additional signifier is shown within the actually and finally realized visual form of the total shots and scenes of the movie, which is being shown on the screen as all elements of the movie are cooperating. While the additional signified is the mental perception that is created inside the mind of the audience.

The success of the communication process depends on the capability of the cinematographer to uploading his elements with the required message and meaning, and the success of all that to affect the audience. 


\section{1-23 February, $2020 \quad$ Rome, Italy}

The previous showed that the search for the minimal units of cinematography will be in the first level of meaning, that doesn't deny the presence of minimal units inside the image projected on the screen like framing, key of light and contrast but they aren't the units that we are looking for as they hold a meaning within themselves and during their display, for instance; displaying an image of high contrast gives a significant meaning of self-struggle, fear or action and other dramatic and signifying meanings.

So the units we are looking for appear in the level of denotation (the $1^{\text {st }}$ level of the meaning) with its original signifier and signified. What we are looking for is basic units that has no meaning within themselves but the meaning appears when they combine together.

Some researchers during their studies of film semiology limited denotation to framing, camera movements and lighting effects. But By following the steps of preparing a shot to be with a scary or terrifying signification at the first level of meaning, it could be analyzed as follows:

Cinematographer requires to realize a definite signification which is (fear) to achieve that meaning, he uses his tools (letters). First he chooses the most appropriate lighting unit which will deliver the meaning such as dido light. Second he decides the camera such as Mini Alexa L.S and sets it in the right way, for example; 1000 ISO with lens opening F 2.8. Third he gets the required color; he could choose CTO for example.

Each choice the cinematographer takes is specifying the minimal cinematic unit that resembles phonemes and graphemes. As each unit of those units doesn't has a meaning independently, on its own but only when they gather together with other units, those units might be other lighting units, or units related to camera settings or color selection. That's how cinematic visual words and sentences are formed by combining all those minimal units through shots, scenes and sequences of the movie.

Any change of any unit of those minimal units will lead to change of the meaning. Changing the lighting color from cold blue to hot red will create a various meaning linked to love, struggle, wars or warmth which are totally contrasting the meaning that blue color brings to the shot.

"Be careful an awful monster will come out of that darkness" when saying or reading that sentence, we mean the meant meaning of it. By introducing certain visual image like the use of low key lighting and wide area of darkness we deliver the same meaning only with different language. Where the movie counted on his minimal units that formed that meaning inside the visual sentence "be careful an awful monster will come out of that darkness". 


\section{1-23 February, $2020 \quad$ Rome, Italy}

At the connotation during the movie display, the audience might anticipate the type of movie within the first sequence of scenes. Isn't that a proof that films have linguistic capabilities through the visual elements? Audience rely on their experience which they gained through the repetitive scenes, that now he has a visual storage of visual vocabularies that cinema uses to deliver certain messages.

\section{Cinematographic Paradigmatic and Syntagmatic categorization}

Paradigm represents the vertical axis of the units (each unit is a sign or word). Paradigm is considered a system of connected significations as they are acting like members in definite category on one condition, that each signifier of them must be different from the others in a tangible way.

While Syntagma represents the horizontal dimension of a chain of any connected units according to rules and norms that are agreed upon to create a whole concept, which is the result of an organized linking process among numbers of interactive significations that are forming words with meaning (sometime it is called a chain). (Chandler, 2002, p:288) A sentence in a language is considered a combination of words.

Combinations that concern the optical signs can exist along in the place, a sign for 2 kids leaving school, through an image of their shadows that could be unite with a red triangle or any road sign that gives the meaning "watch out, a school). Metz uses the term syntagma as a general term to identify the units of independent narration, which is the pattern through which solo shots can be collected, with keeping both "sequence and scene" to identify certain types of syntagmas. (Stam, et al., 1992, p.40) Here we face 2 problems; the first one is imagining that cinema semiology leans towards the syntagmatic axis more than the paradigmatic axis as Metz did. The second problem is applying the paradigmatic model only on the editing, followers of that direction think that the resulted unity is deriving its meaning from its relation with other parts of the paradigmatic model, this is the case that appears with the dissolve within the frames of connecting two sequences.

\section{5-1- that classification allows the study of cinematography as follows:}

vertical paradigm appears in the choices of cinematographers before starting the filming process, the choice of HMI lamp carries the meaning of daylight, while dido light or dinky gives a sensation of the night. That's a clear realization of paradigmatic axis, where cinematographer chooses among the various units what suits his goals. The delicate nature of lighting could be changed infinitely within the shot; same thing could be applied on the rest of cinematography elements. It is enough to change one of those units during the shot in order to get a whole different image, that's so different from the first one. 


\section{1-23 February, $2020 \quad$ Rome, Italy}

Minimal units in cinematography combine at the horizontal syntagmatic axis so they have a meaning in their relation with the other minimal units. The use of HMI lamp as key light and the addition of fill in light gives a sense of manifestation and more important that it controls the degree of contrast (high/low) which is the responsible ratio that is directly related to the drama. Adding gelatin to the main light source, changes the color of the lighting to realize the time and add a dramatic meaning too. Which is a direct realization of the syntagmatic axis in combining the minimal units in cinematography to give a meaning.

Changing any minimal unit among the available choices of the cinematographer, changes the meaning at each time, while placing the chosen one beside the other choices creates a total meaning, which appears during the solo shot, group of shots and the whole movie as well.

Both Paradigmatic and Syntagmatic categories appear when describing and analyzing the semiology of cinematography. Hence we can say that at the first order of signification (denotation) paradigmatic axis appears as cinematographers chooses some definite minimal units among a large number of choices, which will later create the visual sentence which will be loaded with the meaning. While the second order of signification (connotation) will appear in the Syntagmatic axis by combining all those minimal units to realize the required significance meaning.

With that perspective a film shot can't be considered an analogue for the word, the word penknife means "penknife" while the shot of a penknife doesn't mean only penknife but it carries a signification of a whole sentence which is "this is the weapon of the crime that the murderer is going to use" that's how it resembles a whole meaningful sentence.

\section{Articulation and cinematography}

Minimal units term falls under another semiotic term that studies levels of meaning and it is called articulation. A message has articulation if it can be divided into vocabs that have meaning and create the sign coding, which is divided into the minimal units (that carry no meaning on its own) and appears at the second articulation. Codes should have the first articulation so the minimal units existing in level 2 could unite to form a sign/ significant, meaningful sign. Minimal units combine to be a part of bigger units, that interaction of those 2 articulations explains how a language is produced through its fortune of unlimited significations.

Mets thinks that there is nothing so special about a movie that depends entirely on, the same concept of main vocal units, "phenomes" combining to produce meaningful units, cinematic shots or even solo images have significations without depending on combination. 


\section{1-23 February, 2020 Rome, Italy}

A Shot or a frame is the minimal filming unit, in that case they already carry a meaning as he said, so it can't be considered minimal units, which lead Metz to refuse the presence of minimal units in a film. That resulted in limiting the study of cinema semiology to displayed images after the phase of shooting. While the shot is a collective element that can be decomposed to smaller elements, cinematography is one of those elements.

Eco talks about Triple Articulations in the code of cinematic image, where image contains the first articulation which Eco calls "semes" "meaningful units" that could be realizedfor example (a gangster who wears a raincoat) which can be divided into a second articulation of a smaller iconic sign such as (a cigarette hanging from his lips), which can be analyzed at the end into a third articulation that is about awareness. (Stam, et al., 1992, p.33 ) Eco realized in his explanation of the idea of triple articulation that the displayed shot on the screen can be divided into smaller visual elements, but he also dealt with the movie in the post-production and didn't mention the pre-production phase, in addition; the example that he mentioned only handles one element of the optical, visual elements on the screen while elements of forming a shot are more than that from directing, décor, filming, production, costumes and accessories).

Metz thinks that cinematic coding depends on catalyzing signs that lack double articulation. As he declared that in a movie it is impossible to divide the signifier without getting isomorphic parts from the signified, not on the level of the significate.

Phonemes in features movies are special units without its own meaning, their existence alone includes a large distance between the content and the expression. While distance in cinema is too short. Signifier is an image, significate is what this image presents, adding to that the precision of the process of cinematography which gives the image its own probability of being real, and the psychological mechanisms of participation which confirms the impression of reality, shrinking distances even more. So it will be impossible to disassemble the signifier without reaching isomorphic parts of the significate, hence comes the impossibility of second articulation. (Metz, 1991, p.61)

That way of seeing cinema limits it to realism. While cinema in fact doesn't represent reality or a copy of it. If we assume a scene with low key lighting that accompanies the case of the death of one of the characters in the movie, that type of lighting and that contrast between light and darkness, doesn't really exist in similar situations. What cinematic lighting presents is a free creativity that is totally different from reality. Hence cinematography has catalysts and second articulations.

That's what appears in the film language as well and the optical image too. They contain those 2 levels of articulations. Film codes like the code of high key lighting and its relation to romantic movies or light comedy, that is a code that has first level of articulation, the 
minimal units that don't carry meaning within themselves like lighting units, camera settings and color, those are determined after being used as signs with significations and meaning.

\section{Conclusions:}

- Syntagmatic axis realization on elements of cinematography is a proof on the presence of minimal units, without them that axis would have never been realized.

- Cinematography has photocinemes that are meaningless but they become meaningful when they combine with other minimal units, any change at any of those minimal units of cinematography leads to a change in the meaning which confirms the linguistic of cinema.

- at the first order of signification (denotation), the paradigmatic axis appears while cinematographer chooses some definite minimal units among large number of choices, which will later form the visual sentence that will be uploaded with the meaning. While the second order of signification (connotation) appears at the syntagmatic axis from combining those minimal units to realize the required significate meaning.

- Both Paradigmatic and Syntagmatic categories appear when describing and analyzing the semiology of cinematography.

- What cinematic lighting presents is a free creativity that is totally different from reality. Hence cinematography has motivated signs and second articulations.

- The presence of minimal units in cinematography declines the suspicion of cinema has no language in general.

- Linguistic minimal units are limited with certain number of letters while cinematic minimal units are infinite.

- Linguistic minimal units are submitted to grammatical rules while cinematic minimal units are submitted to optical and technological rules.

- cinematic minimal units aren't represented in the shot, a shot isn't a word, it is a whole sentence.

- Minimal units in cinematography don't have a meaning of its own in an individual way but they get a meaning as they unite together with other units. 


\section{References:}

1. Stam, R., Burgoyne, R. \& Flitterman-Lewis, S. (1992). New Vocabularies in Film Semiotics. London. Routledge press.

2. Chandler, Daniel. (2002). The Basics, semiotics, London, Routledge press.

3. Metz, C. (1991). Film Language: A Semiotics of the Cinema, (Michael Taylor, Trans.) Chicago.The university of Chicago Press. 